Pol. J. Food Nutr. Sci., 2019, Vol. 69, No. 3, pp. 235-246

DOI: $10.31883 /$ pjfns/109423 http://journal.pan.olsztyn.pl

Original research article

Section: Food Chemistry

\title{
Microwave-Assisted Extraction of Different Groups of Phenolic Compounds from Grape Skin Pomaces: Modeling and Optimization
}

\author{
Natka Ćurko*, Karla Kelšin, Verica Dragović-Uzelac, Davor Valinger, Marina Tomašević, Karin Kovačević Ganić \\ University of Zagreb, Faculty of Food Technology and Biotechnology, Pierottijeva 6, 10000 Zagreb, Croatia
}

Key words: microwave-assisted extraction (MAE), grape skin pomace, phenolic compounds, antioxidant capacity, artificial neural network (ANN), response surface methodology (RSM)

A microwave-assisted extraction (MAE) technique was employed on grape skin pomaces to enable the extraction of different groups of phenolic compounds (total phenolics, tannins, flavonols, and hydroxycinnamic acids) and to obtain extracts with the highest antioxidant capacity (ORAC). The single-step extraction process was modeled and optimized by means of artificial neural network (ANN) and response surface methodology (RSM) coupled with full factorial design. Methanol concentration $(20$ to $100 \%, \mathrm{v} / \mathrm{v})$, temperature $\left(30\right.$ to $\left.60^{\circ} \mathrm{C}\right)$ and duration $(2$ to 16 min) were MAE input parameters studied. Optimal parameters were further applied in multistep MAE cycles for the complete recovery of phenolic antioxidants. Results showed that methanol concentration was the most significant parameter influencing the extraction of all groups of phenolics and antioxidant capacity of extracts. Moreover, a significant effect of time and temperature was also noticed, except in the case of total hydroxycinnamic acids. The presented ANN model accurately predicted the effect of the three input parameters simultaneously on the output parameters (training $\mathrm{R}^{2}=0.9957$; test $\mathrm{R}^{2}=0.9945$; validation $\left.\mathrm{R}^{2}=0.9965\right)$. Optimal parameters showed that higher methanol concentrations and lower temperatures $\left(100 \%, \mathrm{v} / \mathrm{v}\right.$; at $\left.40^{\circ} \mathrm{C}\right)$ were more convenient for the extraction of flavonols and hydroxycinnamic acids than for ORAC $\left(78.1 \%, \mathrm{v} / \mathrm{v}\right.$; at $\left.60^{\circ} \mathrm{C}\right)$ or total phenolics and tannins $\left(62.7\right.$ and $65.3 \%, \mathrm{v} / \mathrm{v}$; at $\left.60^{\circ} \mathrm{C}\right)$. The number of MAE cycles was found to be a key factor for completing extraction of skin pomace phenolics and should always be considered prior to analytical determination.

\section{LIST OF ABBREVIATIONS}

MAE, Microwave assisted extraction; ANN, Artificial neural network; RSM, Response surface methodology; TP, Total phenolics; TT, Total tannins; THCA, Total hydroxycinnamic acids; TF, Total flavonols; ORAC, Oxygen radical absorbance capacity; GAE, Gallic acid equivalents; and TE, Trolox equivalents.

\section{INTRODUCTION}

Winemaking is one of the most important agricultural sectors worldwide, and according to the latest data collected by the OIV (International Organisation of Vine and Wine) 73.3 million tons of grapes (around 52\% as wine grapes) in 2017, and about 279 million hectoliters of wine were produced in 2018 [OIV, 2018]. Grape pomace is the main solid organic waste from the wine industry, where large quantities are generated after fermentation and pressing, representing about 20\% of the initial grape weight [Ky et al., 2014; Laufenberg et al., 2003]. Only 30 to $40 \%$ of phenolic compounds are extracted during vinification depending mainly on grape cultivar and applied technology of wine production [Deng et al.,

\footnotetext{
* Corresponding Author: Tel.: +38514605 031, Fax: +38514605 072;

E-mail: ncurko@pbf.hr (Prof. N. Curko)
}

2011; Ky et al., 2014; Tournour et al., 2015; Valls et al., 2017]. This means that grape pomace still exhibits high levels of bioactive compounds (60-70\%) with strong antioxidant, antibacterial, and cytotoxic activities as well as favorable pharmacological properties [Bartolomé et al., 2004; Peixoto et al., 2018]. These compounds are known to contribute to human health and are particularly associated with reduced incidence of cardiovascular diseases as atherosclerosis and hypertension, neurodegeneration, and similar medical conditions [Auger et al., 2004; De Sales et al., 2018; Rodriguez-Rodriguez et al., 2012]. Grape skins pomace proved to be a good source of anthocyanins, hydroxycinnamic acids, flavanols and flavonols, whereas flavanols are the most abundant seed polyphenols [Kammerer et al., 2004; Ky et al., 2014]. As a result of the increased concern over the sustainability of agricultural practices, efforts have been made to enable the use of grape pomaces bioactive extracts in various segments of food, pharmaceutical and cosmetic industry, resulting in applications such as natural antioxidant, source of natural pigments, additive in wine production, functional ingredient, etc. [Beres et al., 2017; Ky \& Teissedre, 2015]. Thus, it is necessary to have efficient extraction methods to achieve high recoveries of phenolic compounds that allow quality control of obtained extracts through their analysis and characterization.

Microwave-assisted extraction (MAE) has been investigated and proposed as better than conventional extraction 
in terms of extraction efficiency, time, and solvent consumption [Chan et al., 2011]. Also, it has been introduced for a wide range of bioactive compounds from food by-products and natural sources, and likewise for the extraction of polyphenols from grape [Hong et al., 2001; Karvela et al., 2009; Krishnaswamy et al., 2013; Liazid et al., 2011] and grape pomace [Casazza et al., 2010; Medouni-Adrar et al., 2015; Pedroza et al., 2015]. Nevertheless, in most of the aforementioned studies conducted on grape or pomace, target compounds were total phenolics, while the mode of operation was focused to the power level of microwave irradiation. This means that extraction was carried out at fixed power usually ranging from 300 to $550 \mathrm{~W}$ [Hong et al., 2001; Krishnaswamy et al., 2013; Medouni-Adrar et al., 2015] and in some cases even up to $900 \mathrm{~W}$ [Pedroza et al., 2015] and at pre-determined extraction time ranging from 200 to $1003 \mathrm{~s}$ [Hong et al., 2001; Krishnaswamy et al., 2013; Medouni-Adrar et al., 2015; Pedroza et al., 2015]. However, the mode of operation that focuses on the extraction temperature rather than microwave power (meaning that extraction temperature is set at desired point by regulating microwave power) is more suitable for the extraction of different groups of thermo-sensitive phenolics [Chan et al., 2011], while temperatures lower than $60^{\circ} \mathrm{C}$ are recommended in order to avoid possible degradations [Liazid et al., 2011; Pedroza et al., 2015]. In addition, beside the microwave power and temperature, solvent nature and extraction time also showed to be important factors influencing the performance of MAE [Liazid et al., 2011]. Ethanol is, by far, the most used solvent as a good microwave absorber [Chan et al., 2011; Krishnaswamy et al., 2013; Pedroza et al., 2015], while on the other hand, there are only few studies of MAE of grape and pomace phenolics with methanol [Casazza et al., 2010; Hong et al., 2001]. Nevertheless, methanol compared to ethanol extracted higher concentrations of total phenolics, $O$-diphenols and flavonoids, in both grape skin and seed pomace [Casazza et al., 2010], and showed to be a more selective solvent in conventional extraction of phenolic compounds [Pinelo et al., 2005]. In addition, considering the time parameter, earlier studies showed that prolongation of extraction time beyond the optimal conditions was not useful to extract more phenolic compounds [Mané et al., 2007; Medouni-Adrar et al., 2015]. However, prolongation of the extraction time to ensure the completion of extraction and reduced risk of thermal degradation can be achieved through the repeating of the extraction step in multistep MAE [Chan et al., 2011]. The effect of cycle number was only examined by Pedroza et al. [2015] revealing that two irradiation cycles $\left(900 \mathrm{~W}, 1003 \mathrm{~s}\right.$, with temperature fluctuating up to $80^{\circ} \mathrm{C}$ ) were necessary to achieve the equivalent yield of total phenolics with reference solid-liquid extraction; while to the best of our knowledge effects of sequential irradiation cycles with lower power and temperature on the matrix of grape skin pomace were not earlier studied. In addition, modeling and optimization of MAE extraction condition is usually performed through response surface methodology (RSM) [Krishnaswamy et al., 2013; Medouni-Adrar et al., 2015] and artificial neural network (ANN) methods [Ameer et al., 2017]. RSM can demonstrate interaction effects of inherent MAE parameters on target responses, whereas ANN can reliably model the MAE process with better predictive and estimation capabilities.
The aim of the present study was to model and optimize single-step MAE (methanol concentration, temperature and time) of phenolic antioxidants (total phenolics, tannins, hydroxycinnamic acids, flavonols, and ORAC value) from grape skin pomaces by using ANN and RSM, and to further apply optimal parameters in multiple steps in order to study effects of sequential irradiation cycles and to develop a method for the complete recovery of phenolic antioxidants.

\section{MATERIALS AND METHODS}

\section{Chemicals}

Methanol, ethanol, and hydrochloric acid were purchased from Carlo Erba (Val del Reuil, France). Folin-Ciocalteu's phenol reagent was purchased from Reagecon (Shannon, Ireland), and 2,2'-azobis(2-methylpropionamidine) dihydrochloride (AAPH) from Acros (Gell, Belgium). Sodium carbonate, sodium dihydrogen phosphate, disodium hydrogen phosphate, fluorescein, 6-hydroxy-2,5,7,8-tetramethylchroman-2-carboxylic acid (Trolox), gallic acid, caffeic acid, and quercetin were purchased from Sigma-Aldrich (St. Louis, MO, USA).

\section{Grape skin pomace sample preparation}

This study was conducted on grape skin pomaces from Cabernet Sauvignon, Merlot, and Teran cultivars (Vitis vinifera L.). Grape pomaces were provided from Agrolaguna winery (Poreč, Croatia), obtained as wine by-products after alcoholic fermentation and pressing; from grapes harvested in technological maturity in September 2014 and originating out of Istria vine-growing sub-region area (Croatia). Grape pomace samples were first frozen $\left(-80^{\circ} \mathrm{C}\right)$ and then freezedried (vacuum 0.130 to $0.155 \mathrm{hPa}$, temperature -30 to $0^{\circ} \mathrm{C}$ for $24 \mathrm{~h}$, isothermal desorption at $20^{\circ} \mathrm{C}$ for $12 \mathrm{~h}$ ) using Christ Alpha 1-4 LSC Plus freeze-dryer (Osterode am Hatz, Germany). Freeze-dried skins were manually separated from seeds and pulp, and ground with an electric grinder. Grape skin powders particle size distributions measured by the laser particle size analyzer (Malvern, Mastersizer 2000, Germany) were: (i) Cabernet Sauvignon $\mathrm{d}(0.9) \leq 354.31 \mu \mathrm{m}, \mathrm{d}(0.5) \leq$ $123.03 \mu \mathrm{m}, \mathrm{d}(0.1) \leq 7.66 \mu \mathrm{m}$; (ii) Merlot $\mathrm{d}(0.9) \leq 376.54 \mu \mathrm{m}$, $\mathrm{d}(0.5) \leq 146.90 \mu \mathrm{m}, \mathrm{d}(0.1) \leq 8.37 \mu \mathrm{m}$; and (iii) Teran $\mathrm{d}(0.9) \leq$ $365.55 \mu \mathrm{m}, \mathrm{d}(0.5) \leq 130.70 \mu \mathrm{m}, \mathrm{d}(0.1) \leq 8.26 \mu \mathrm{m}$. Samples were stored at $-20^{\circ} \mathrm{C}$ before subsequent analyses.

\section{Microwave-Assisted Extraction (MAE)}

Phenolic compounds from grape skin pomace were extracted using a professional single-mode microwave reactor (Milestone, Start S Microwave Labstation for Synthesis, Sorisole, Italy), with an adjustable microwave power output, operating at $2.45 \mathrm{GHz}$; equipped with an air and water reflux condenser and a magnetic stirrer. Parameters that were kept constant during extractions were: stirring (at 80\%) and ventilation after extraction (1 $\mathrm{min}$ ), as well as liquid to solid ratio (50:1), selected based on literature data [Hong et al., 2001; Li et al., 2011; Medouni-Adrar et al., 2015] and preliminary experiment (data not shown). Operating extraction mode was focused to the extraction temperature that was set at the desired point, meaning that power was used to maintain the temperature in the reaction cell, rather than being 
applied at continuous level, since this mode reduces the risk of thermal degradation, and is more suitable for the extraction of thermo-sensitive compounds [Chan et al., 2011]. A portion of $0.5 \mathrm{~g}$ of freeze-dried grape skin pomace powder and $25 \mathrm{~mL}$ of the solvent were added to $50 \mathrm{~mL}$ round bottom flask with double neck and a cooling system. MAE was performed at first according to the experimental design shown in Table 1 in order to determine optimal variables (parameters) of single-step MAE. Secondly, the optimal parameters determined were applied in multiple steps (sequential repetitive extraction cycles) in order to define the necessary number of MAE cycles in the final multistep MAE method for the complete extraction of phenolic compounds.

\section{Experimental design for modeling and optimization of single- -step MAE}

Full factorial design comprising 27 experiments was used to evaluate the effect of three independent variables and to obtain optimal conditions of a single cycle. Independent process variables were: solvent polarity (methanol concentration in methanol-water mixture, $\mathrm{v} / \mathrm{v}$ ), extraction time (min) and temperature $\left({ }^{\circ} \mathrm{C}\right)$; named as $\mathrm{X}_{1}, \mathrm{X}_{2}$, and $\mathrm{X}_{3}$, respectively (Table 1). Each experiment in experimental design was run in duplicate $[54(27 \times 2)$ experiments in total]. Ranges of variables were: solvent polarity at 20\%, $60 \%$ and $100 \%$ (v/v) methanol; time at 2, 9 and $16 \mathrm{~min}$; and temperature at 30,45 and $60^{\circ} \mathrm{C}$, as listed in Table 1 . The responses (output variables) determined were concentrations of extracted phenolics and antioxidant capacity of skin pomace extracts (Table 1). All experiments were conducted on grape skin pomace of Cabernet Sauvignon. After each MAE experiment (Table 1), the mixture was transferred to a centrifugation tube and centrifuged at $4000 \mathrm{rpm}$ for $5 \mathrm{~min}$ on a Rotofix 32 instrument (Hettich Zentrifugen, Germany). Liquid (solvent) was evaporated at $30^{\circ} \mathrm{C}$, the residue was dissolved in water and freeze-dried after which grape skin pomace extracts were obtained.

\section{Application of sequential irradiation cycles (multistep MAE)}

Optimal parameters of a single MAE cycle were performed in eight sequential consecutive cycles (eight-step MAE) in all three cultivars (Cabernet Sauvignon, Merlot, and Teran), following the earlier described protocol. In total, eight irradiation cycles were tested, since the significant increase in concentrations of phenolic compounds between $7^{\text {th }}$ and $8^{\text {th }}$ cycle was not established, while relative recovery for $8^{\text {th }}$ cycle accounted for less than $1 \%(\mathrm{w} / \mathrm{w}$, relative recovery was calculated relative to overall amount obtained after eight cycles). Average calculated power of each cycle was $47.3 \mathrm{~W}$. After each MAE cycle, the mixture was transferred to a centrifugation tube and centrifuged as earlier mentioned. The solid part was separated and re-used for MAE with a fresh solvent in a recurring manner. Liquid (solvent) maintained after each cycle was separately evaporated at $30^{\circ} \mathrm{C}$, and the residue was dissolved in water and freeze--dried. Concentration and relative recovery $(\%, \mathrm{w} / \mathrm{w})$ of total phenolics were determined in extracts after each single cycle of multistep MAE and expressed cumulatively. The multistep MAE procedure was run in triplicate for each cultivar.

\section{Spectrophotometric analyses}

Spectrophotometric analyses were conducted with a double-beam UV-1600PC spectrophotometer (VWR International, China). Freeze-dried grape pomace skin extracts were solubilized in a wine model solution [Ćurko et al., 2014; Ky \& Teissedre, 2015] at concentrations of $3 \mathrm{~g} / \mathrm{L}$ and $0.25 \mathrm{~g} / \mathrm{L}$ for analyses of total phenolics (TP) and tannins (TT), respectively; as well as at $7 \mathrm{~g} / \mathrm{L}$ for analyses of total flavonols (TF) and hydroxycinnamic acids (THCA). Total phenolics were determined with the Folin-Ciocalteu method [Singleton \& Rossi, 1965] and results were expressed in mg of gallic acid equivalents (GAE) per g of dry weight (dw) grape skin pomace. Concentrations of total tannins were measured by acid hydrolysis and expressed in $\mathrm{mg}$ per $\mathrm{g}$ of dry weight (dw) grape skin pomace [Ribéreau-Gayon \& Stonestreet, 1966]. Total hydroxycinnamic acids and flavonols concentrations were determined by measuring absorbance at 320 and $360 \mathrm{~nm}$ according to the method described by Mazza et al. [1999]. Results were expressed in mg of caffeic acid equivalents (CAE) per $\mathrm{g}$ of $\mathrm{dw}$; and $\mathrm{mg}$ of quercetin equivalents (QE) per $\mathrm{g}$ of $\mathrm{dw}$ grape skin pomace, for the concentrations of THCA and TF, respectively. All spectrophotometric analyses were conducted in triplicate.

\section{Oxygen Radical Absorbance Capacity (ORAC) Assay}

The oxygen radical absorbance capacity (ORAC) was determined according to Ninfali et al. [2005], as briefly described by Mazor Jolić et al. [2011]. Results were calculated as ORAC values using the differences of areas under fluorescein decay curve between the blank and the sample. The results were expressed as $\mu \mathrm{mol}$ Trolox equivalent (TE) per $\mathrm{g}$ of dw grape skin pomace.

\section{Data analysis}

Statistical analysis of analytical data was carried out by the Analysis of Variance (ANOVA) using Statistica v.10.0 software (Statsoft Inc., Tulsa, OK, USA). Tukey's HSD Test was used as a comparison test when samples were significantly different after ANOVA $(p<0.05)$. To test whether it is possible to predict phenolic and antioxidant characteristics of grape skin pomace based on three input variables (methanol concentration, temperature, and duration of process) artificial neural network modeling was applied. Multiple layer perceptron networks were developed in Statistica v.10.0 software (StatSoft Inc, Tulsa, OK, USA). Response surface methodology (RSM) was used to determine the optimal combination of process parameters which varied at three levels. Experimental data were analyzed using DesignExpert (C) software (Stat-Ease, Inc., MN, USA) and fitted to an empirical second-order polynomial regression model:

$$
Y=\beta_{0}+\sum \beta_{i} X_{i}+\sum \beta_{i i} X_{i}^{2}+\sum \beta_{i j} X_{i} X_{j}
$$

where: $\mathrm{y}$ is the predicted response concentration of TP, TT, THCA, TF and ORAC; $\beta_{0}, \beta_{i}, \beta_{i i}$ and $\beta_{i j}$ are regression coefficients for intercept, linear, quadratic and interaction terms respectively; and $X_{\mathrm{i}}$ and $X_{\mathrm{j}}$ are the actual levels of the independent variables. Based on the regression model, three-dimensional re- 
sponse surface methodology (RSM) plots of optimal extraction conditions for TP, TT, THCA, TF and ORAC were designed.

\section{RESULTS AND DISCUSSION}

Effect of process variables on the extraction yields of phenolic compounds and antioxidant capacity of grape skin pomace extracts

Systematic study was carried out based on the experimental design presented in Table 1, in order to evaluate the effects of different MAE process variables, i.e. solvent (methanol) concentration, temperature and time, on the extraction yields of different groups of phenolics and antioxidant capacity of grape skin pomace extracts.

In addition, polynomial equations and statistical parameters describing the effect of operating process variables on the phenolic and antioxidant characteristics of grape skin pomace extracts are presented in Table 2.

High values of $R^{2}$ presented in Table 2 indicated a very good correlation between experimental values and values of models that could explain more than $90 \%$ of the variation. Moreover, very low $p$-values indicated that each generated model was statistically significant, suggesting that MAE could be well described with presented models.

Analyses of experimental data revealed that all three process (input) variables, that is solvent, time and temperature, significantly influenced the MAE of TP and TT $(p<0.05)$. In addition, analogous qualitative trends were detected for both output variables (TP, TT) indicating a similar behavior toward variation of solvent concentration and temperature. Experiments performed with $60 \%(\mathrm{v} / \mathrm{v})$ methanol extracted significantly higher concentrations of TP and TT compared to the ones with the identical time and temperature using 20\% $(\mathrm{v} / \mathrm{v})$ methanol. Interestingly, an increase in methanol concentration up to $100 \%(\mathrm{v} / \mathrm{v})$ did not further increase the concentrations of target compounds in both cases. Contrary, concentrations of TP and TT extracted with 100\% (v/v) methanol were lower than the ones obtained with $60 \%(\mathrm{v} / \mathrm{v})$ methanol. A similar type of behavior was observed by Yilmaz \& Toledo [2006] for the conventional extraction of grape seeds polyphenols, where the highest concentrations were obtained by $60 \%$ or $70 \%(\mathrm{v} / \mathrm{v})$ methanol. Moreover, $60 \%(\mathrm{v} / \mathrm{v})$ methanol is most commonly applied in two-step conventional extraction of grape and pomace tannins [Chira et al., 2009; Ky et al., 2014]. Results obtained may be attributed to the changes of solvent polarity, and consequently changes in solubility and diffusivity of TP and TT. In addition, significant differences between the $60 \%$ and $100 \%(\mathrm{v} / \mathrm{v})$ methanol samples of identical extraction time were obtained at $45^{\circ} \mathrm{C}$ and $60^{\circ} \mathrm{C}$, while the same trends among $60 \%$ and $100 \%(\mathrm{v} / \mathrm{v})$ methanol samples of identical extraction time were not observed at the lower temperature $\left(30^{\circ} \mathrm{C}\right)$ (Table 1$)$. Furthermore, an increase in the applied temperature $\left(30-45-60^{\circ} \mathrm{C}\right)$ resulted in a significant increase of both TP and TT concentrations among the experiments performed under identical conditions of solvent concentration and time. Exceptionally, in the case of $100 \%(\mathrm{v} / \mathrm{v})$ methanol, an increase of the temperature caused only a slight increase of TP and TT concentrations. Namely, the increase in the temperature favored the extraction by en- hancing both the solubility of solute and the diffusion coefficient [Pinelo et al., 2005]; and as a consequence, the highest concentrations of TP and TT were determined at the highest temperature tested $\left(60^{\circ} \mathrm{C}\right)$. However, temperature range was kept relatively low (maximum $60^{\circ} \mathrm{C}$ ) and was not further increased in order to avoid possible degradation of phenolic compounds as well as denaturation of membranes [Liazid et al., 2011; Pedroza et al., 2015]. This showed to be particularly important for the extraction of flavonoids that were found to be more sensitive to the degradation caused by high temperature and long extraction time [Casazza et al., 2010]. Furthermore, the time variable differently affected the extraction trends of TP and TT. Prolongation of extraction time from 2 to $9 \mathrm{~min}$ among the experiments performed under identical conditions positively affected the extraction of both TP and TT, particularly for the experiments conducted with $60 \%(\mathrm{v} / \mathrm{v})$ methanol. However, further prolongation from 9 to 16 min only slightly increased concentration of TP, but at the same time negatively affected extraction of TT. Namely, concentrations of TT extracted after 16 min were lower than the ones obtained after 9 min under identical conditions, where a significant decrease was found for $60 \%(\mathrm{v} / \mathrm{v})$ methanol at higher temperatures $\left(45\right.$ and $60^{\circ} \mathrm{C}$ ) as well as for $100 \%(\mathrm{v} / \mathrm{v})$ methanol at $60^{\circ} \mathrm{C}$. As earlier mentioned [Casazza et al., 2010], results obtained confirmed the sensitivity of TT, indicating that temperatures higher than $60^{\circ} \mathrm{C}$ and extraction time longer than 9 min should be avoided in the case of single-step MAE of TT. This phenomenon could be explained by Fick's second law of diffusion, when the solvent oversaturates, and concentration gradient becomes null after a particular duration; while further augmentation of extraction time may favor degradation reactions and thus decrease in concentration of phenolic compounds [Medouni-Adrar et al., 2015]. Hence, excessive extraction time was not useful to extract more phenolic compounds [Mané et al., 2007; Pinelo et al., 2005]. Finally, the highest values of TP were reached at the conditions of $60 \%(\mathrm{v} / \mathrm{v})$ methanol and $60^{\circ} \mathrm{C}$ after 9 or 16 min of extraction, while the highest values of TT were extracted under identical conditions of methanol concentration and temperature but only after 9 min of MAE.

Likewise, methanol concentration also had a significant influence $(p<0.05)$ on the extraction of THCA and TF, but trends established were quite different from those noticed for the TP. As it can be seen in Table 1, an increase in methanol concentration significantly promoted the extraction of THCA and TF, and the highest concentrations were thus extracted with $100 \%(\mathrm{v} / \mathrm{v})$ methanol. In addition, temperature and time had no significant effect on the extraction of THCA, but did affect the extraction of TF. Concentrations of TF extracted at $45^{\circ} \mathrm{C}$ were higher than those extracted at $30^{\circ} \mathrm{C}$ or $60^{\circ} \mathrm{C}$. Time variable influenced the extraction of TF in similar manner as earlier proposed for TT (Table 1), since the highest concentrations were obtained after 9 min of MAE, while prolongation up to $16 \mathrm{~min}$ led to a decrease in TF content. Decreased concentration of phenolic compounds induced by the prolongation of extraction time was previously reported in the literature [Liazid et al., 2011]. This decrease could be ascribed to oxidative degradation of polyphenols, particularly the ones having a greater number of hydroxyl-type substituents in the B ring (like myricetin-3-O- 
TABLE 1. Operating process variables of microwave-assisted extraction (MAE) experimental design and their effect on phenolic and antioxidant characteristics of grape skin pomace extracts.

\begin{tabular}{|c|c|c|c|c|c|c|c|c|}
\hline \multirow{3}{*}{$\begin{array}{l}\text { Exp. } \\
\text { no. }\end{array}$} & \multicolumn{3}{|c|}{ Operating input variables } & \multicolumn{5}{|c|}{ Output variables } \\
\hline & $\mathrm{X}_{1}$ & $\mathrm{X}_{2}$ & $\mathrm{X}_{3}$ & $\mathrm{TP}$ & $\mathrm{TT}$ & THCA & $\mathrm{TF}$ & ORAC \\
\hline & $\begin{array}{l}\text { Methanol } \\
\text { conc. (\%) }\end{array}$ & $\begin{array}{l}\text { Time } \\
(\mathrm{min})\end{array}$ & $\begin{array}{l}\text { Temp } \\
\left({ }^{\circ} \mathrm{C}\right)\end{array}$ & $\begin{array}{c}\text { (mg GAE/g } \\
\text { dw skin pomace) }\end{array}$ & $\begin{array}{c}(\mathrm{mg} / \mathrm{g} \\
\mathrm{dw} \text { skin pomace }) \\
\end{array}$ & $\begin{array}{c}\text { (mg/g } \\
\text { dw skin pomace) }\end{array}$ & $\begin{array}{c}(\mathrm{mg} / \mathrm{g} \\
\mathrm{dw} \text { skin pomace }) \\
\end{array}$ & $\begin{array}{c}(\mu \mathrm{mol} \mathrm{TE} / \mathrm{g} \\
\mathrm{dw} \text { skin pomace })\end{array}$ \\
\hline 1 & 20 & 2 & 30 & $3.77 \pm 0.12^{\mathrm{n}}$ & $1.00 \pm 0.06^{\mathrm{m}}$ & $0.06 \pm 0.04^{\mathrm{ef}}$ & $0.07 \pm 0.01^{\mathrm{g}}$ & $70.18 \pm 0.84^{\mathrm{n}}$ \\
\hline 2 & 60 & 2 & 30 & $8.98 \pm 0.28^{\mathrm{ij}}$ & $7.60 \pm 0.20^{\mathrm{gh}}$ & $0.44 \pm 0.13^{\text {bcde }}$ & $0.47 \pm 0.05^{\mathrm{f}}$ & $127.78 \pm 2.77^{\mathrm{jk}}$ \\
\hline 3 & 100 & 2 & 30 & $8.42 \pm 0.17 \mathrm{jk}^{\mathrm{k}}$ & $7.38 \pm 0.23^{\mathrm{h}}$ & $3.22 \pm 0.03^{\mathrm{a}}$ & $3.22 \pm 0.25^{\mathrm{bc}}$ & $124.83 \pm 3.63^{\mathrm{jk}}$ \\
\hline 4 & 20 & 9 & 30 & $4.62 \pm 0.29^{\mathrm{mn}}$ & $2.36 \pm 0.09^{\mathrm{Im}}$ & $0.30 \pm 0.05^{\text {bcdef }}$ & $0.16 \pm 0.03^{\mathrm{g}}$ & $80.71 \pm 1.64^{\mathrm{mn}}$ \\
\hline 5 & 60 & 9 & 30 & $10.68 \pm 0.22^{\mathrm{fgh}}$ & $9.64 \pm 0.21^{\mathrm{ef}}$ & $0.34 \pm 0.09^{\text {bcdef }}$ & $0.50 \pm 0.06^{\mathrm{ef}}$ & $154.58 \pm 7.64$ \\
\hline 6 & 100 & 9 & 30 & $10.08 \pm 0.26^{\text {fghi }}$ & $8.48 \pm 0.24^{\mathrm{fgh}}$ & $3.04 \pm 0.05^{\mathrm{a}}$ & $3.73 \pm 0.06^{\mathrm{a}}$ & $149.76 \pm 2.14^{i}$ \\
\hline 7 & 20 & 16 & 30 & $5.13 \pm 0.12^{\mathrm{mn}}$ & $2.27 \pm 0.19^{\mathrm{gm}}$ & $0.19 \pm 0.11^{\mathrm{def}}$ & $0.13 \pm 0.05^{\mathrm{g}}$ & $97.61 \pm 0.47^{\mathrm{lm}}$ \\
\hline 8 & 60 & 16 & 30 & $11.56 \pm 0.44^{\mathrm{def}}$ & $9.14 \pm 0.47^{\mathrm{efg}}$ & $0.33 \pm 0.08^{\text {bcdef }}$ & $0.47 \pm 0.02^{\mathrm{f}}$ & $181.71 \pm 5.20^{\mathrm{h}}$ \\
\hline 9 & 100 & 16 & 30 & $10.66 \pm 0.84^{\mathrm{fgh}}$ & $7.24 \pm 0.74^{\mathrm{hi}}$ & $2.72 \pm 0.11^{\mathrm{a}}$ & $3.67 \pm 0.07^{\mathrm{a}}$ & $178.23 \pm 4.06^{\mathrm{h}}$ \\
\hline 10 & 20 & 2 & 45 & $5.86 \pm 0.34^{\operatorname{lm}}$ & $2.95 \pm 0.08^{\mathrm{kl}}$ & $0.02 \pm 0.00^{\mathrm{f}}$ & $0.11 \pm 0.01^{\mathrm{g}}$ & $102.44 \pm 3.62^{1}$ \\
\hline 11 & 60 & 2 & 45 & $13.06 \pm 0.44^{\mathrm{d}}$ & $12.47 \pm 0.34^{\mathrm{d}}$ & $0.60 \pm 0.05^{\mathrm{bc}}$ & $0.69 \pm 0.04^{\mathrm{de}}$ & $198.85 \pm 6.93^{\mathrm{gh}}$ \\
\hline 12 & 100 & 2 & 45 & $9.79 \pm 0.27^{\text {ghij }}$ & $8.57 \pm 0.35^{\text {efgh }}$ & $2.86 \pm 0.07^{\mathrm{a}}$ & $3.36 \pm 0.10^{\mathrm{bc}}$ & $185.52 \pm 7.59^{\mathrm{gh}}$ \\
\hline 13 & 20 & 9 & 45 & $7.30 \pm 0.48^{\mathrm{kl}}$ & $4.99 \pm 0.16^{\mathrm{j}}$ & $0.11 \pm 0.03^{\mathrm{ef}}$ & $0.24 \pm 0.06^{\mathrm{g}}$ & $110.32 \pm 1.20^{\mathrm{kl}}$ \\
\hline 14 & 60 & 9 & 45 & $14.82 \pm 0.54^{c}$ & $15.15 \pm 0.33^{\mathrm{c}}$ & $0.58 \pm 0.07^{\mathrm{bcd}}$ & $0.75 \pm 0.06^{\mathrm{d}}$ & $230.52 \pm 3.63^{\mathrm{e}}$ \\
\hline 15 & 100 & 9 & 45 & $10.99 \pm 0.41^{\mathrm{efg}}$ & $9.15 \pm 0.74^{\mathrm{efg}}$ & $3.07 \pm 0.17^{\mathrm{a}}$ & $3.86 \pm 0.07^{\mathrm{a}}$ & $206.53 \pm 6.06^{\mathrm{fg}}$ \\
\hline 16 & 20 & 16 & 45 & $8.48 \pm 0.15^{\mathrm{j} \mathrm{jk}}$ & $4.39 \pm 0.20^{\mathrm{jk}}$ & $0.15 \pm 0.03^{\text {ef }}$ & $0.18 \pm 0.04^{g}$ & $115.69 \pm 1.00^{\mathrm{kl}}$ \\
\hline 17 & 60 & 16 & 45 & $16.20 \pm 0.29^{c}$ & $12.11 \pm 0.23^{\mathrm{d}}$ & $0.40 \pm 0.10^{\text {bcdef }}$ & $0.58 \pm 0.06^{\text {def }}$ & $269.77 \pm 4.43^{\mathrm{bc}}$ \\
\hline 18 & 100 & 16 & 45 & $11.59 \pm 0.45^{\mathrm{def}}$ & $8.45 \pm 0.10^{\mathrm{fgh}}$ & $2.91 \pm 0.18^{\mathrm{a}}$ & $3.74 \pm 0.06^{\mathrm{a}}$ & $237.70 \pm 1.58^{\mathrm{de}}$ \\
\hline 19 & 20 & 2 & 60 & $9.30 \pm 0.36^{\text {hij }}$ & $5.77 \pm 0.10^{\mathrm{j}}$ & $0.17 \pm 0.07^{\text {ef }}$ & $0.16 \pm 0.04^{g}$ & $128.48 \pm 2.83^{\mathrm{jk}}$ \\
\hline 20 & 60 & 2 & 60 & $19.19 \pm 0.14^{b}$ & $15.93 \pm 0.66^{c}$ & $0.61 \pm 0.09^{\mathrm{b}}$ & $0.61 \pm 0.03^{\text {def }}$ & $225.74 \pm 5.38^{\mathrm{ef}}$ \\
\hline 21 & 100 & 2 & 60 & $11.01 \pm 0.49^{\text {efg }}$ & $10.08 \pm 0.57^{\mathrm{e}}$ & $2.73 \pm 0.08^{a}$ & $3.16 \pm 0.04^{c}$ & $199.37 \pm 7.65^{\text {gh }}$ \\
\hline 22 & 20 & 9 & 60 & $10.78 \pm 0.68^{\text {efgh }}$ & $8.21 \pm 0.64^{\mathrm{fgh}}$ & $0.25 \pm 0.08^{\text {bcdef }}$ & $0.19 \pm 0.03^{\mathrm{g}}$ & $137.19 \pm 2.33^{\mathrm{ij}}$ \\
\hline 23 & 60 & 9 & 60 & $21.39 \pm 0.29^{\mathrm{a}}$ & $21.66 \pm 0.37^{\mathrm{a}}$ & $0.45 \pm 0.05^{\text {bcde }}$ & $0.65 \pm 0.05^{\mathrm{def}}$ & $257.02 \pm 5.57^{\mathrm{cd}}$ \\
\hline 24 & 100 & 9 & 60 & $12.36 \pm 0.26^{\mathrm{de}}$ & $13.02 \pm 0.71^{\mathrm{d}}$ & $2.83 \pm 0.26^{\mathrm{a}}$ & $3.39 \pm 0.10^{b}$ & $246.52 \pm 9.28^{\mathrm{de}}$ \\
\hline 25 & 20 & 16 & 60 & $11.54 \pm 0.02^{\mathrm{def}}$ & $7.69 \pm 0.04^{\mathrm{gh}}$ & $0.21 \pm 0.09^{\text {cdef }}$ & $0.17 \pm 0.04^{g}$ & $142.65 \pm 5.72^{\mathrm{ij}}$ \\
\hline 26 & 60 & 16 & 60 & $22.16 \pm 0.68^{\mathrm{a}}$ & $19.61 \pm 0.49^{b}$ & $0.61 \pm 0.08^{b}$ & $0.59 \pm 0.06^{\text {def }}$ & $302.25 \pm 9.36^{\mathrm{a}}$ \\
\hline 27 & 100 & 16 & 60 & $12.99 \pm 0.44^{\mathrm{d}}$ & $9.72 \pm 0.14^{\mathrm{ef}}$ & $2.77 \pm 0.01^{\mathrm{a}}$ & $3.28 \pm 0.03^{\mathrm{bc}}$ & $280.87 \pm 7.70^{\mathrm{b}}$ \\
\hline
\end{tabular}

Data are expressed as average value over two replications \pm standard deviation. ANOVA to compare data; different letters indicate significant difference between grape skin pomace extracts (Tukey's test, $\mathrm{p}<0.05$ ). Abbreviations: TP, total phenolics; TT, total tannins; THCA, total hydroxycinnamic acids; TF, total flavonols; ORAC, oxygen radical absorbance capacity; GAE, gallic acid equivalents; TE, Trolox equivalents.

-glucoside and procyanidins) that showed to be less stable to oxidation and more easily degradable [Crupi et al., 2018].

Methanol concentration, time, and temperature significantly influenced the antioxidant activity (ORAC) of grape skin pomace extracts $(p<0.05)$, while trends found were close to those earlier established for TP. The highest concentrations were extracted with $60 \%$ (v/v) methanol, while significantly lower ORAC values were generally found in experiments using $100 \%$ and particularly $20 \%$ (v/v) methanol (on average 2-fold lower) under identi- cal conditions of temperature and time. Moreover, an increase in the temperature and time contributed to an increase in ORAC values of grape skin pomace extracts. Namely, the antioxidant activity of extracts significantly increased in the range of 30-45$-60^{\circ} \mathrm{C}$ and $2-9-16 \mathrm{~min}$ for temperature and time, respectively. Results obtained are in accordance with findings from an earlier study of Pinelo et al. [2005] who reported a higher DPPH inhibition percentage for methanol extracts compared to water or ethanol ones. The same authors showed that temperature had 
TABLE 2. Polynomial equations and statistical parameters describing the effect of operating process variables and on the phenolic and antioxidant characteristics of grape skin pomace extracts.

\begin{tabular}{|c|c|c|c|}
\hline Output variables & $2^{\text {nd }}$-order polynomial equation (quadratic model) & $\mathrm{R}^{2}$ & $p$-value \\
\hline TP (mg GAE/g dw skin pomace) & $\begin{aligned} 15.26 & -1.73 \mathrm{X}_{1}+1.16 \mathrm{X}_{2}+3.16 \mathrm{X}_{3}-0.02 \mathrm{X}_{1} \mathrm{X}_{2}-0.91 \mathrm{X}_{1} \mathrm{X}_{3} \\
& +0.08 \mathrm{X}_{2} \mathrm{X}_{3}-6.19 \mathrm{X}_{1}^{2}-0.35 \mathrm{X}_{2}^{2}+0.47 \mathrm{X}_{3}^{2}\end{aligned}$ & 0.9191 & $<0.0001$ \\
\hline TT (mg/g dw skin pomace) & $\begin{aligned} 14.54+ & 2.36 \mathrm{X}_{1}+0.49 \mathrm{X}_{2}+3.14 \mathrm{X}_{3}-0.44 \mathrm{X}_{1} \mathrm{X}_{2}-0.53 \mathrm{X}_{1} \mathrm{X}_{3} \\
& +0.21 \mathrm{X}_{2} \mathrm{X}_{3}-6.94 \mathrm{X}_{1}^{2}-1.83 \mathrm{X}_{2}^{2}+0.57 \mathrm{X}_{3}^{2}\end{aligned}$ & 0.9237 & $<0.0001$ \\
\hline THCA (mg/g dw skin pomace) & $\begin{aligned} 0.55+ & 1.35 \mathrm{X}_{1}-0.01 \mathrm{X}_{2}+0.02 \mathrm{X}_{3}-0.03 \mathrm{X}_{1} \mathrm{X}_{2}-0.03 \mathrm{X}_{1} \mathrm{X}_{3} \\
& +0.02 \mathrm{X}_{2} \mathrm{X}_{3}+1.03 \mathrm{X}_{1}^{2}-0.07 \mathrm{X}_{2}^{2}+0.02 \mathrm{X}_{3}^{2}\end{aligned}$ & 0.9911 & $<0.0001$ \\
\hline $\mathrm{TF}$ (mg/g dw skin pomace) & $\begin{aligned} 0.76+ & 1.67 \mathrm{X}_{1}+0.05 \mathrm{X}_{2}-0.01 \mathrm{X}_{3}+0.07 \mathrm{X}_{1} \mathrm{X}_{2}-0.08 \mathrm{X}_{1} \mathrm{X}_{3} \\
& -0.03 \mathrm{X}_{2} \mathrm{X}_{3}+1.24 \mathrm{X}_{1}^{2}-0.13 \mathrm{X}_{2}^{2}-0.13 \mathrm{X}_{3}^{2}\end{aligned}$ & 0.9954 & $<0.0001$ \\
\hline ORAC ( $\mu \mathrm{mol} \mathrm{TE} / \mathrm{g} \mathrm{dw}$ skin pomace) & $\begin{array}{c}224.09+47.78 X_{1}+24.63 X_{2}+41.93 X_{3}+11.02 X_{1} X_{2}+ \\
9.51 X_{1} X_{3}+3.12 X_{2} X_{3}-61.21 X_{1}^{2}+1.30 X_{2}^{2}-12.73 X_{3}^{2} \\
\end{array}$ & 0.9695 & $<0.0001$ \\
\hline
\end{tabular}

Abbreviations: TP, total phenolics; TT, total tannins; THCA, total hydroxycinnamic acids; TF, total flavonols; ORAC, oxygen radical absorbance capacity; GAE, gallic acid equivalents; TE, Trolox equivalents.

a critical role in the extraction efficiency, where the value of $50^{\circ} \mathrm{C}$ maximized the antiradical activity of phenolic extracts. Furthermore, solvent concentration, time, and microwave power, and interaction of power with time and solvent concentration, as well as interaction of time and solvent concentration showed to play a significant role in the antioxidant activity of grape seed extracts [Krishnaswamy et al., 2013]. Our results demonstrated that the extract with the highest phenolics content, that was extracted under $60 \%(\mathrm{v} / \mathrm{v})$ methanol and the highest temperature $\left(60^{\circ} \mathrm{C}\right)$ and the longest process duration $(16 \mathrm{~min})$, exhibited the highest antioxidant activity.

\section{Modeling single-step MAE by artificial neural network (ANN)}

In order to test whether it is possible to predict the concentrations of total phenolics, tannins, flavonols, and hydroxycinnamic acids as well as the antioxidant capacity based on methanol concentration, temperature, and duration of the process, several AANs were developed. In all the cases, three variables were used as input data (methanol concentration, tempera- ture, and duration of the process) and 5 variables were used as output data (TT, TP, THCA, TF and ORAC). The ANN training was performed with random separation of data into training, test, and validation sets as 60:20:20 ratio. Back error propagation algorithm available in Statistica v.10.0 was applied for the model training and model performance was evaluated based on $\mathrm{R}^{2}$ and Root Mean Squared Error (RMSE) values for training, test, and validation [Benković et al., 2015]. Examples of few developed ANNs are given in Table 3.

Almost all of the developed networks had a high linear correlation coefficient $\left(\mathrm{R}^{2}\right)$ for training, test, and validation. The five selected ones (Table 3 ) had the highest $\mathrm{R}^{2}$ values for training, test, and validation with lowest RMSE values. It may be observed that there are basically two different ANNs regarding the number of neurons in the hidden layer ( 8 and 10) since all of them have 3 neurons in the input layer and 5 neurons in the output layer. Also the hidden activation and the output activation of the ANNs with same numbers of neurons in the hidden layer were different. When looking at the correlation coefficients for training, for all of the five networks,

TABLE 3. Characteristics of five selected artificial neural networks (ANNs) based on coefficients of determination and root mean square errors for the prediction of phenolic and antioxidant characteristics of grape skin pomace extracts obtained by microwave-assisted extraction (MAE).

\begin{tabular}{lccc|ccc}
\hline Network number & 1 & 2 & 3 & 4 & 5 \\
\hline Network name* & MLP 3-10-5** & MLP 3-10-5 & MLP 3-8-5 & MLP 3-10-5 & MLP 3-8-5 \\
Training performance & 0.9957 & 0.9947 & 0.9951 & 0.9958 & 0.9919 \\
Training error & 0.0016 & 0.0020 & 0.0018 & 0.0015 & 0.0029 \\
Test performance & 0.9945 & 0.9918 & 0.9925 & 0.9939 & 0.9863 \\
Test error & 0.0020 & 0.0040 & 0.0022 & 0.0017 & 0.0040 \\
Validation performance & 0.9965 & 0.9954 & 0.9964 & 0.9965 & 0.9936 \\
Validation error & 0.0026 & 0.0034 & 0.0028 & 0.0031 & 0.0054 \\
Training algorithm & BFGS103 & BFGS66 & BFGS100 & BFGS128 & BFGS69 \\
Hidden activation & Logistic & Tanh & Tanh & Logistic & Logistic \\
Output activation & Exponential & Exponential & Exponential & Identity & Exponential \\
\hline
\end{tabular}

*In the network name, the first number describes the number of input variables, the second one the number of neurons in the hidden layer and the third one number of output variables. ${ }^{* *}$ The most suitable artificial neural network. Abbreviations: MLP, multi layered perceptron. 
the highest value was observed for ANN $4\left(\mathrm{R}^{2}=0.9958\right)$ which also had the lowest training error $(\mathrm{RMSE}=0.0015)$. ANN 1 which had slightly lower training performance $\left(\mathrm{R}^{2}=0.9957\right)$ had the highest value for test performance $\left(\mathrm{R}^{2}=0.9945\right)$. The highest value for validation performance was observed for ANN 1 $\left(\mathrm{R}^{2}=0.9965\right)$ and ANN $4\left(\mathrm{R}^{2}=0.9965\right)$ which had the same values but the ANN 1 had lower validation error $(\mathrm{RMSE}=0.0026)$. Based on these results, ANN 1 was selected as the optimal one. The comparison between experimental and predicted values of TP, TT, THCA, TF, and ORAC for the most suitable ANN 1 (MLP 3-10-5) is presented in Figures 1a-d respectively, while correlation coefficients for prediction of TT, TP, THCA, TF, and ORAC are presented in Table 4.

From Figure 1 it is clearly visible that the ANN managed to achieve a high correlation between experimental data and ANN predictions for each parameter (TP, TT, THCA, TF,

TABLE 4. Correlation coefficients of the most suitable artificial neural network* for the prediction of phenolic and antioxidant characteristics of grape skin pomace extracts.

\begin{tabular}{l|c|c|c}
\hline \multirow{2}{*}{$\begin{array}{l}\text { Output } \\
\text { variables }\end{array}$} & \multicolumn{3}{|c}{ Correlation coefficient $\left(\mathrm{R}^{2}\right)$} \\
\cline { 2 - 4 } & Training & Testing & Validation \\
\hline TP & 0.9943 & 0.9893 & 0.9981 \\
TT & 0.9928 & 0.9900 & 0.9981 \\
THCA & 0.9973 & 0.9978 & 0.9916 \\
TF & 0.9991 & 0.9978 & 0.9988 \\
ORAC & 0.9952 & 0.9979 & 0.9962 \\
\hline
\end{tabular}

*The most suitable artificial neural network: ANN 1 (MLP 3-10-5). Abbreviations: TP, total phenolics; TT, total tannins; THCA, total hydroxycinnamic acids; TF, total flavonols; ORAC, oxygen radical absorbance capacity.
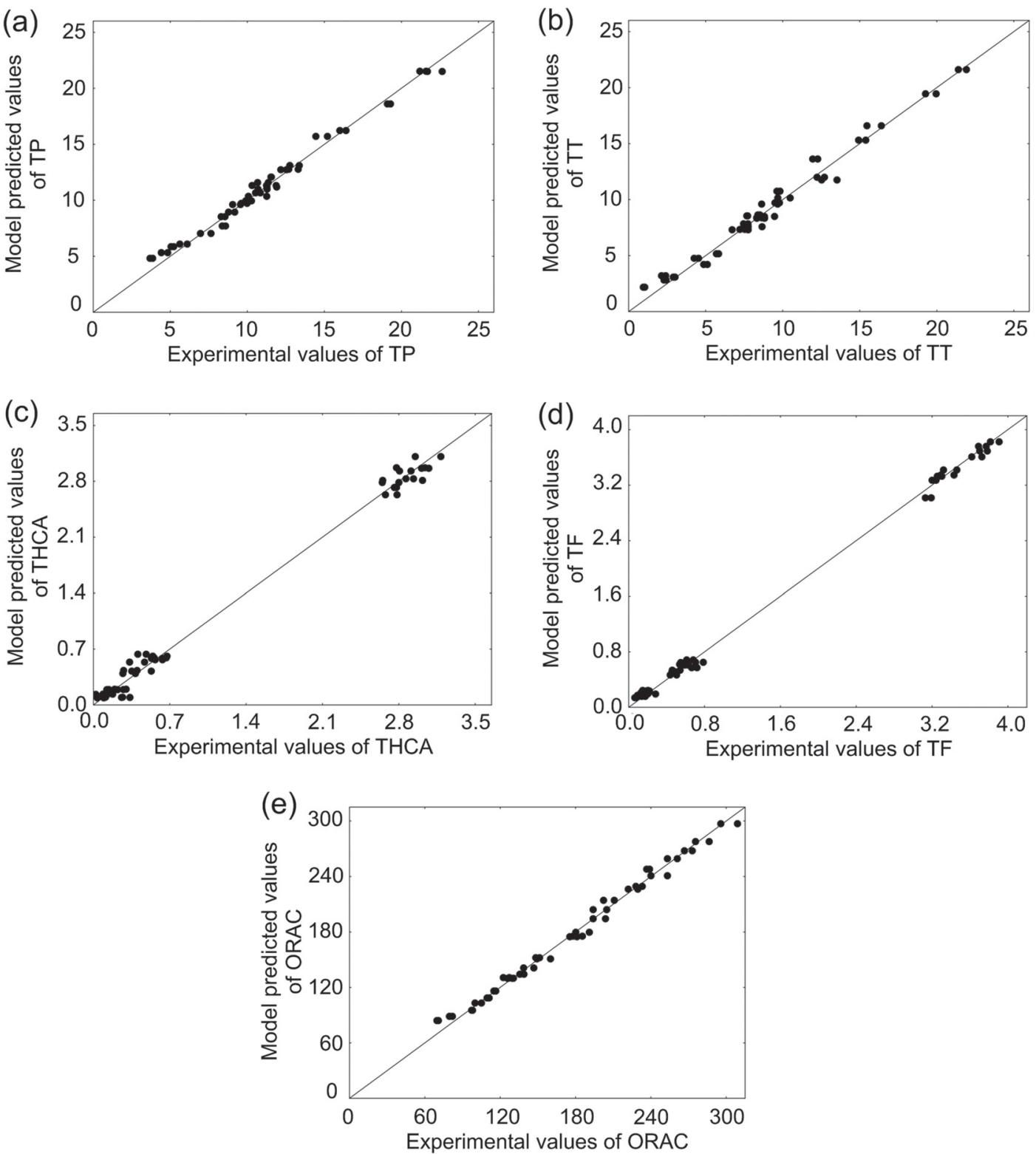

FIGURE 1. Comparison between experimental and predicted values of the most suitable ANN 1 (MLP 3-10-5) for: (a) total phenolics (TP), (b) total tannins (TT), (c) total hydroxycinnamic acids (THCA), (d) total flavonols (TF), and (e) oxygen radical absorbance capacity (ORAC). 
and ORAC). From Table 4 it is visible that the best correlations between experimental data and the ANN predictions were obtained for TF with the $\mathrm{R}^{2}$ values of $0.9991,0.9978$, and 0.9988 for training, test, and validation, respectively. The second highest value for validation was observed for TP $\left(\mathrm{R}^{2}=0.9981\right)$ and TT $\left(\mathrm{R}^{2}=0.9981\right)$ which had the same value, followed by ORAC $\left(\mathrm{R}^{2}=0.9962\right)$ and THCA $\left(\mathrm{R}^{2}=0.9916\right)$. Considering that those are very high values obtained for validations for all the tested parameters, these models could easily be used to monitor extraction processes since a goodfitting model or quantitative model would have $\mathrm{R}^{2}$ values above 0.90 and quantitative models are compact representations where a single differential or difference equation may describe the performance of the system for a large set of input functions and initial states [Lunze, 1998]. This is not surprising since ANNs were proven to be one of the most useful tools in extraction processes for monitoring, predicting, and optimizing different compounds in microwave-assisted or ultrasound-assisted extractions like phenolic compounds from Achillea berbresteinii [Salarbashi et al., 2014]; total polyphenolic compounds from chokeberries [Simić et al., 2016]; as well as total extract, stevioside, and rebaudioside A from Stevia rebaudiana (Bertoni) leaves [Ameer et al., 2017].

\section{Optimization of single-step MAE by response surface methodology (RSM) and effects of sequential irradiation cycles}

In order to provide overall optimal conditions of simultaneous and maximum extraction of phenolic antioxidants from grape skins, various output responses were first considered at the same time. However, desirability function (D), which is the most important and applied multicriteria methodology in optimization procedures [Bezerra et al., 2008], of this joint model was importantly lower $(\mathrm{D}=0.7870)$ compared to $\mathrm{D}$ values obtained by each individual model. Also, earlier it has been shown that optimal conditions can vary significantly among the different phenolic groups [Karvela et al., 2009]. Hence, the individual models developed (Table 2) were used to optimize the parameters of MAE process. Optimal conditions were selected using desirability for the maximum concentrations of phenolic compounds and antioxidant capacity of grape skin pomace extracts. Three-dimensional (a)

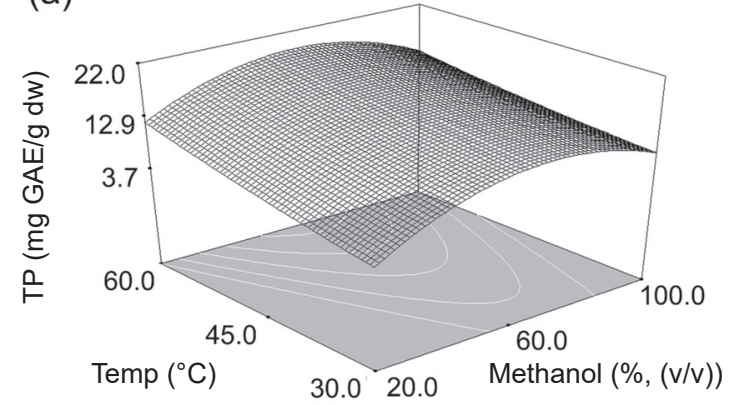

(c)

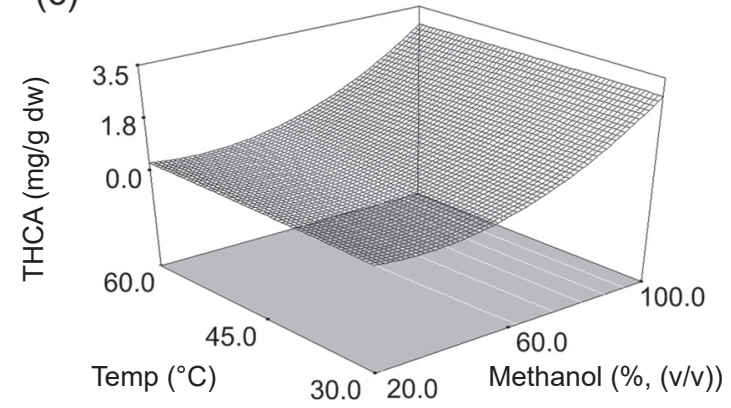

(b)

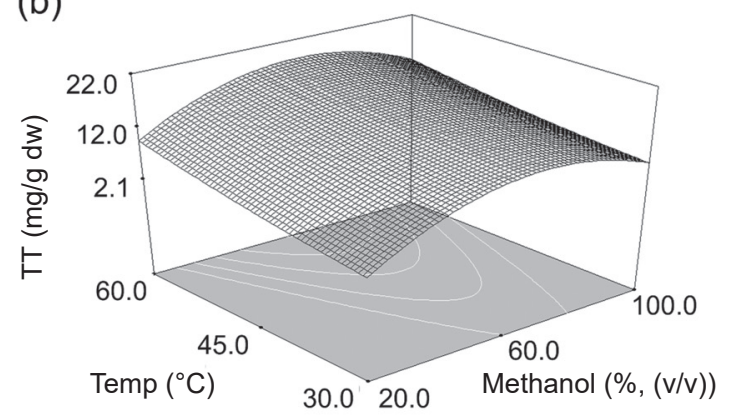

(d)

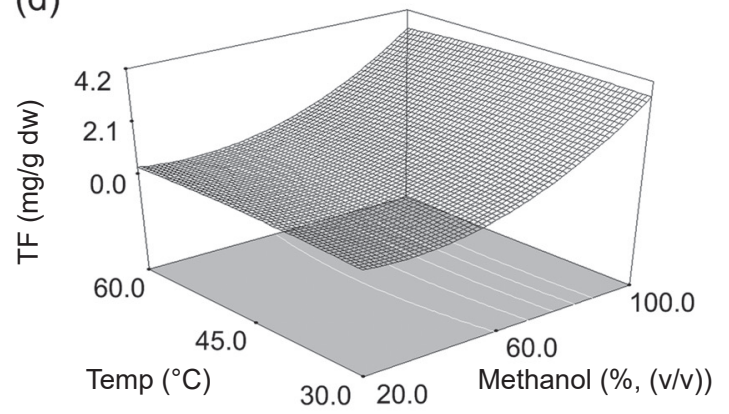

(e)

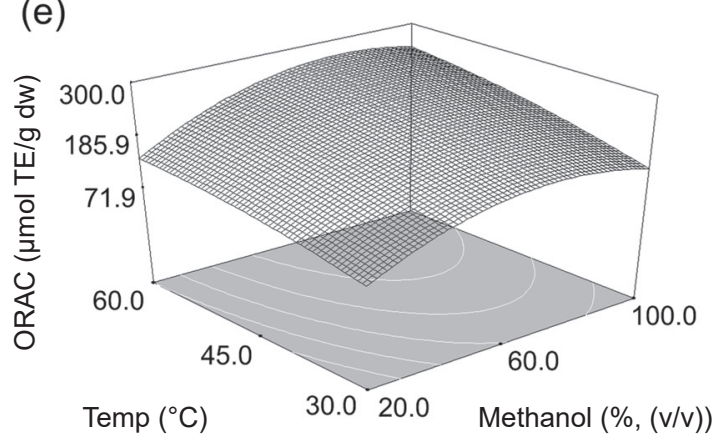

FIGURE 2. RSM plots of the models developed for single-step MAE of: (a) total phenolics (TP), (b) total tannins (TT), (c) total hydroxycinnamic acids (THCA), (d) total flavonols (TF), and (e) oxygen radical absorbance capacity (ORAC). 
response surface plots were created for each variable individually and optimum conditions of single-step MAE for maximum response of TP, TT, THCA and TF, as well maximum antioxidant capacity of extracts (ORAC) are presented in Figures $2 \mathrm{a}$-e. Given to the results that prolongation of single-step extraction time was not useful to extract more polyphenols as well as to optimize the overall time of multistep final method, all plots were generated by keeping the time variable to the fixed value $(9 \mathrm{~min})$ and plotting it against two other variables (methanol concentration and temperature). Optimal conditions for single-step MAE were $62.7 \%$ and $65.3 \%(\mathrm{v} / \mathrm{v})$ methanol for TP and TT, respectively, at $60^{\circ} \mathrm{C}$ for $9 \mathrm{~min}$ with the predicted yields of 18.91 and $18.38 \mathrm{mg} / \mathrm{g}$ $\mathrm{dw}$ skin pomace for the first and the latter (Figures 2a and b). Optimal conditions for single-step MAE of THCA and TF were $100 \%$ (v/v) methanol, at $40^{\circ} \mathrm{C}$ for 9 min with the predicted yields of 2.94 and $3.68 \mathrm{mg} / \mathrm{g}$ dw skin pomace for THCA and $\mathrm{TF}$, respectively (Figures $2 \mathrm{c}$ and $\mathrm{d}$ ). Optimal conditions for the maximum antioxidant capacity of extracts (ORAC) by single-step MAE were $78.1 \%$ (v/v) methanol, at $60^{\circ} \mathrm{C}$ for 9 min with the predicted yields of $265.77 \mu \mathrm{mol} \mathrm{TE} / \mathrm{g}$ dw skin pomace (Figure 2e). Validity of predicted optimal values for each output variable were experimentally confirmed. Experimental and predicted values of optimal conditions were given in Table 5. Experimental data were in accordance with the predicted ones, since predicted and experimental values were not significantly different within the $95 \%$ confidence interval.

Effects of sequential irradiation cycles were further studied on three different cultivars (Cabernet Sauvignon, Merlot, and Teran) by application of optimal conditions of a single MAE cycle in multiple steps (cycles) on the model of TP covering all phenolic compounds. Application of sequential irradiation cycles allowed the prolongation of the extraction time [Chan et al., 2011] but without risk of degradation due to the joint effects of temperature and longer extraction time [Medouni-Adrar et al., 2015; Pinelo et al., 2005]. Also, it is important to note that this was manipulated by the ad-
TABLE 5. Phenolic and antioxidant characteristics of grape skin pomace extracts obtained by optimized single-step microwave-assisted extraction conditions.

\begin{tabular}{lcc}
\hline Output variables & $\begin{array}{c}\text { Experimental } \\
\text { concentrations }\end{array}$ & $\begin{array}{c}\text { Predicted } \\
\text { concentrations }\end{array}$ \\
\hline $\begin{array}{l}\text { TP } \\
\text { (mg GAE/g dw skin pomace) }\end{array}$ & $19.05 \pm 0.27$ & 18.91 \\
$\begin{array}{l}\text { TT } \\
\text { (mg/g dw skin pomace) }\end{array}$ & $18.18 \pm 0.35$ & 18.38 \\
$\begin{array}{l}\text { THCA } \\
\text { (mg/g dw skin pomace) }\end{array}$ & $3.02 \pm 0.09$ & 2.94 \\
$\begin{array}{l}\text { TF } \\
\text { (mg/g dw skin pomace) }\end{array}$ & $3.70 \pm 0.05$ & 3.68 \\
$\begin{array}{l}\text { ORAC } \\
\text { ( } \mathrm{mmol} \mathrm{TE/g} \mathrm{dw} \mathrm{skin} \mathrm{pomace)}\end{array}$ & $261.04 \pm 5.32$ & 265.77 \\
\hline
\end{tabular}

Abbreviations: TP, total phenolics; TT, total tannins; THCA, total hydroxycinnamic acids; TF, total flavonols; ORAC, oxygen radical absorbance capacity; GAE, gallic acid equivalents; TE, Trolox equivalents.

dition of fresh solvent to the residue and repeating the extraction step. This procedure allowed us to avoid the solvent evaporation earlier reported [Pedroza et al., 2015], and ensured the completion of extraction, so that the MAE method could be applied prior to analytical determination. Effects of eight sequential irradiation extraction cycles on the extraction of total phenolics (concentration and relative recovery $(\%, \mathrm{w} / \mathrm{w})$ - calculated relative to the overall amount obtained after eight cycles) are presented in Table 6.

The major part of TP was extracted in the first extraction step $\left(1^{\text {st }}\right)$, and then less and less TP were extracted in each successive individual cycle. Concentrations in each cycle decreased in the order: Cabernet Sauvignon, Teran, Merlot. On the other hand, very similar values of relative recovery were found after the second cycle independently of cultivar, meaning that $\%(\mathrm{w} / \mathrm{w})$ of extracted TP were quite similar for all three cultivars. For example, $\sim 83 \%$ (w/w) of TP were cumulatively extracted after three cycles in all three cultivars, and around 90\% and 94\% (w/w) of TP, after four and five cycles, respec-

TABLE 6. Cumulative effect of sequential irradiation cycles on the extraction of total phenolics (concentration and relative recovery) from Cabernet Sauvignon, Merlot, and Teran grape skin pomaces.

\begin{tabular}{|c|c|c|c|c|c|c|}
\hline \multirow[b]{2}{*}{ Cycle number } & \multicolumn{2}{|c|}{ Cabernet Sauvignon } & \multicolumn{2}{|c|}{ Merlot } & \multicolumn{2}{|c|}{ Teran } \\
\hline & $\begin{array}{c}\text { TP } \\
\text { (mg GAE/g } \\
\text { dw skin pomace) }\end{array}$ & $\begin{array}{l}\mathrm{TP} \\
(\%)\end{array}$ & $\begin{array}{c}\text { TP } \\
\text { (mg GAE/g } \\
\text { dw skin pomace) }\end{array}$ & $\begin{array}{l}\mathrm{TP} \\
(\%)\end{array}$ & $\begin{array}{c}\mathrm{TP} \\
\text { (mg GAE/g } \\
\text { dw skin pomace) }\end{array}$ & $\begin{array}{l}\mathrm{TP} \\
(\%)\end{array}$ \\
\hline $1^{\mathrm{st}}$ & $19.05^{\mathrm{m}}$ & 46.4 & $15.18^{\circ}$ & $51.6^{\mathrm{h}}$ & $17.82^{\mathrm{n}}$ & $49.3^{\mathrm{i}}$ \\
\hline $2^{\text {nd }}$ & $28.66^{\mathrm{hi}}$ & $69.7^{\mathrm{g}}$ & $21.17^{1}$ & $71.9^{\mathrm{f}}$ & $25.96^{\mathrm{j}}$ & $71.8^{\mathrm{f}}$ \\
\hline $3^{\text {rd }}$ & $34.05^{\mathrm{e}}$ & $82.9^{\mathrm{e}}$ & $24.30^{\mathrm{k}}$ & $82.5^{\mathrm{e}}$ & $30.22^{\mathrm{g}}$ & $83.6^{\mathrm{e}}$ \\
\hline $4^{\text {th }}$ & $37.07^{\mathrm{c}}$ & $90.2^{\mathrm{d}}$ & $26.58^{j}$ & $90.3^{\mathrm{d}}$ & $32.70^{\mathrm{f}}$ & $90.4^{\mathrm{d}}$ \\
\hline $5^{\text {th }}$ & $38.66^{\mathrm{b}}$ & $94.1^{\mathrm{c}}$ & $27.82^{\mathrm{i}}$ & $94.5^{\mathrm{c}}$ & $34.14^{\mathrm{e}}$ & $94.4^{\mathrm{c}}$ \\
\hline $6^{\text {th }}$ & $40.35^{\mathrm{a}}$ & $98.2^{\mathrm{ab}}$ & $29.03^{\mathrm{h}}$ & $98.6^{\mathrm{ab}}$ & $35.44^{\mathrm{d}}$ & $98.0^{\mathrm{ab}}$ \\
\hline $7^{\text {th }}$ & $40.73^{\mathrm{a}}$ & $99.1^{\mathrm{ab}}$ & $29.21^{\mathrm{gh}}$ & $99.2^{\mathrm{ab}}$ & $35.89^{\mathrm{cd}}$ & $99.3^{\mathrm{ab}}$ \\
\hline $8^{\text {th }}$ & $41.09^{\mathrm{a}}$ & $100.0^{\mathrm{a}}$ & $29.45^{\mathrm{gh}}$ & $100.0^{\mathrm{a}}$ & $36.16^{\mathrm{cd}}$ & $100.0^{\mathrm{a}}$ \\
\hline
\end{tabular}

Data are expressed as average value of three replications \pm standard deviation. ANOVA to compare data among three cultivars; different letters indicate statistical differences between extracts (Tukey's test, $\mathrm{p}<0.05$ ). Abbreviations: TP, total phenolics; GAE, gallic acid equivalents. 
tively (Table 6). In addition, results in Table 6 showed that concentrations cumulatively extracted by sequential irradiation cycles showed a significant increase with the prolongation of extraction cycle number up to six. Further extraction only slightly contributed to the concentrations of TP. Hence, there were no significant differences among the last three cycles. According to these results, the extraction process can finally be limited to six cycles for all three cultivars, that approximately extracted more than $98 \%$ (w/w) of total phenolics. Nevertheless, it is important to note that the number of cycles should not be considered as fixed. Namely, wide ranges in concentrations of different phenolics were detected in extensive studies of grape pomace over the years, comprising variations of cultivar and vintage as well as geographical origin, maturity, and winemaking technology [Deng et al., 2011; Kammerer et al., 2004; Ky et al., 2014; Ky \& Teissedre, 2015]. For instance, these differences can lead even up to ten times lower/higher concentrations of phenolic compounds and antioxidant activity of grape skin pomaces [Ky et al., 2014; Ky $\&$ Teissedre, 2015]. Hence, our results demonstrated the importance of MAE with successive irradiation cycles, particularly for the conditions operating under lower power and temperature, where the exact number should always be examined in order to ensure the completion of the extraction process.

Comparison of our final MAE conditions to literature data for grape skin and pomace was difficult, due to great variation considering the operating systems and parameters studied (extraction solvent, temperature range, power, time, number of irradiation cycles, etc.), thus reflecting to the differences in selected or optimal conditions for extraction of TP [Chan et al., 2011]. For instance, Pedroza et al. [2015] proposed extraction from Chardonnay grape skin pomace with $60 \%$ (v/v) aqueous ethanol solution, and liquid to solid ratio of $4 \mathrm{~mL} / \mathrm{g}$ for $1033 \mathrm{~s}$ at $900 \mathrm{~W}$, in two cycles; while successive irradiation under these conditions caused solvent evaporation and imbibition, and led to decreasing recovery. In our study, in order to avoid these negative effects of sequential irradiation cycles, multistep MAE was performed by the addition of fresh solvent in each repetitive cycle, while extraction was conducted with significantly lower irradiation power and longer time, as well as different solvent. Furthermore, optimal conditions for single-step MAE of TP from Ahmar Bou-Amar grape skin pomace obtained by optimization modeling were $51.45 \%(\mathrm{v} / \mathrm{v})$ acetone, with solid to liquid ratio of $0.1 \mathrm{~g} / 32.25 \mathrm{~mL}$ for $113.74 \mathrm{~s}$ and $384.44 \mathrm{~W}$ [Medouni-Adrar et al., 2015]. Hong et al. [2001] also proposed single-step MAE of TP from grape skin with $90 \%$ (v/v) methanol, solid to liquid ratio of $1 \mathrm{~g} / 15 \mathrm{~mL}$ for $200 \mathrm{~s}$ and $540 \mathrm{~W}$. Overall extraction time $(6 \times 9 \mathrm{~min})$ of our MAE methods was comparable to the study of Casazza et al. [2010] who also worked with a similar operating system, as well as lower power for longer time. Namely, Casazza et al. [2010] performed single-step MAE from Pinot noir grape skin pomace using 100\% (v/v) methanol, with solid-liquid ratio of $0.2 \mathrm{~g} \mathrm{dw} / \mathrm{mL}$ for $60 \mathrm{~min}$ at $110^{\circ} \mathrm{C}$ and $60 \mathrm{~W}$. Concentrations extracted with this single-step extraction at higher temperatures $\left(110^{\circ} \mathrm{C}\right)$ in Pinot Noir skin pomace were slightly lower than those shown in Table 6, probably due to the differences in MAE parameters but also to grape cultivar, maturity, vintage, winemaking technology, etc. [Deng et al., 2011; Kammerer et al., 2004; Ky et al., 2014; Valls et al., 2017]. Concentrations of TP determined in grape skin pomaces of three cultivars decreased in the order: Cabernet Sauvignon, Teran, and Merlot, and were comparable with other studies regardless of the extraction method prior to the analysis. For instance, concentrations of TP found were in line with the values previously reported for Cabernet Sauvignon and Merlot or other red grape cultivars (11.8-54.8 mg GAE/g dw grape skin pomace) [Casazza et al., 2010; Deng et al., 2011; Ky et al., 2014; Medouni-Adrar et al., 2015; Yilmaz \& Toledo, 2006]. Finally, results showed high efficiency of MAE method, which allowed completion of extraction in shorter time compared to time consumed during conventional solid-liquid extraction methods, that for processes with temperatures under $60^{\circ} \mathrm{C}$ can take from 6 to $24 \mathrm{~h}$ [Casazza et al., 2010; Ky et al., 2014].

\section{CONCLUSIONS}

The effects of methanol concentration $(20,60$, and $100 \%$, $\mathrm{v} / \mathrm{v})$, time (2, 9, and $16 \mathrm{~min}$ ), and temperature (30, 45, and $60^{\circ} \mathrm{C}$ ) on the extraction of phenolic antioxidants from grape skin pomace were studied using modeling and optimization by ANN and RSM. All input parameters significantly influenced the MAE of total phenolics, tannins, flavonols, and antioxidant capacity of extracts (ORAC), while extraction yields of hydroxycinnamic acids was markedly influenced only by methanol concentration. The ANN model was accurate to predict the extraction yields of phenolic antioxidants with high correlation coefficients for training $\left(\mathrm{R}^{2}=0.9957\right)$, test $\left(\mathrm{R}^{2}=0.9945\right)$, and validation $\left(\mathrm{R}^{2}=0.9965\right)$, thus confirming that ANN could be successfully used in MAE experiments for monitoring or prediction. The optimal parameters of a single-step MAE cycle for maximum yields of phenolic compounds and antioxidant capacity obtained by RSM were: (i) $62.7 \%$ and $65.3 \%(\mathrm{v} / \mathrm{v})$ methanol for total phenolics and tannins, respectively, at $60^{\circ} \mathrm{C}$ for $9 \mathrm{~min}$; (ii) $100 \%$ (v/v) methanol, at $40^{\circ} \mathrm{C}$ for 9 min for total flavonols and hydroxycinnamic acids; and (iii) $78.1 \%(\mathrm{v} / \mathrm{v})$ methanol, at $60{ }^{\circ} \mathrm{C}$ for $9 \mathrm{~min}$ for ORAC. The number of extraction steps showed to be an important factor influencing extraction yields of phenolic compounds. Relative recovery of total phenolics $(\%, w / w)$ showed to be rather constant extraction parameter for all three cultivars, where six MAE cycles significantly contributed to the concentration of TP and extracted more than $98 \%$ (w/w) of total phenolics. Multistep MAE by optimal parameters proved to be a highly efficient method for the extraction of grape skin pomace phenolics prior to analytical determination.

\section{RESEARCH FUNDING}

This work was supported by means of the project "The application of innovative technologies in the isolation of bioactive compounds from organic waste in the wine production", co-financed by the European Union under the call RC.2.2.08: "Strengthening Capacities for Research, Development and Innovation" funded by the European Regional Development Fund, the Regional Competitiveness Operational Program 2007 - 2013. 


\section{CONFLICT OF INTEREST}

The authors declare no conflict of interest.

\section{REFERENCES}

1. Ameer, K., Bae, S.W., Jo, Y., Lee, H.G., Ameer, A., Kwon, J.H. (2017). Optimization of microwave-assisted extraction of total extract, stevioside and rebaudioside-A from Stevia rebaudiana (Bertoni) leaves, using response surface methodology (RSM) and artificial neural network (ANN) modelling. Food Chemistry, 229, 198-207.

2. Auger, C., Gérain, P., Laurent-Bichon, F., Portet, K., Bornet, A., Caporiccio, B., Cros, G., Teissédre, P.L., Rouanet, J.M. (2004). Phenolics from commercialized grape extracts prevent early atherosclerotic lesions in hamsters by mechanisms other than antioxidant effect. Journal of Agricultural and Food Chemistry, 52 (16), 5297-5302.

3. Bartolomé, B., Nuñez, V., Monagas, M., Gómez-Cordovés, C. (2004). In vitro antioxidant activity of red grape skins. European Food Research and Technology, 218(2), 173-177.

4. Benković, M., Tušek, A. J., Belščak-Cvitanović, A., Lenart, A., Domian, E., Komes, D., Bauman, I. (2015). Artificial neural network modelling of changes in physical and chemical properties of cocoa powder mixtures during agglomeration. LWT - Food Science and Technology, 64(1), 140-148.

5. Beres, C., Costa, G.N.S., Cabezudo, I., da Silva-James, N.K., Teles, A.S.C., Cruz, A.P. G., Mellinger-Silva, C., Tonon, R.V., Cabral, L.M.C., Freitas, S.P. (2017). Towards integral utilization of grape pomace from winemaking process: A review. Waste Management, 68, 581-594.

6. Bezerra, M.A., Santelli, R.E., Oliveira, E.P., Villar, L.S., Escaleira, L.A. (2008). Response surface methodology (RSM) as a tool for optimization in analytical chemistry. Talanta, 76(5), 965-977.

7. Casazza, A.A., Aliakbarian, B., Mantegna, S., Cravotto, G., Perego, P. (2010). Extraction of phenolics from Vitis vinifera wastes using non-conventional techniques. Journal of Food Engineering, 100(1), 50-55.

8. Chan, C.H., Yusoff, R., Ngoh, G.C., Kung, F.W.L. (2011). Microwave-assisted extractions of active ingredients from plants. Journal of Chromatography A, 1218(37), 6213-6225.

9. Chira, K., Schmauch, G., Saucier, C., Fabre, S., Teissedre, P.-L. (2009). Grape variety effect on proanthocyanidin composition and sensory perception of skin and seed tannin extracts from Bordeaux wine grapes (Cabernet Sauvignon and Merlot) for two consecutive vintages (2006 and 2007). Journal of Agricultural and Food Chemistry, 57(2), 545-553.

10. Crupi, P., Dipalmo, T., Clodoveo, M.L., Toci, A.T., Coletta, A. (2018). Seedless table grape residues as a source of polyphenols: comparison and optimization of non-conventional extraction techniques. European Food Research and Technology, 244(6), 1091-1100.

11. Ćurko, N., Kovačević Ganić, K., Gracin, L., Đapić, M., Jourdes, M., Teissedre, P.L. (2014). Characterization of seed and skin polyphenolic extracts of two red grape cultivars grown in Croatia and their sensory perception in a wine model medium. Food Chemistry, 145, 15-22.

12. De Sales, N.F.F., Da Costa, L.S., Carneiro, T.I.A., Minuzzo, D.A., Oliveira, F.L., Cabral, L.M.C., Torres, A.G., El-Bacha, T.
(2018). Anthocyanin-rich grape pomace extract (Vitis vinifera L.) from wine industry affects mitochondrial bioenergetics and glucose metabolism in human hepatocarcinoma HepG2 cells. Molecules, 23(3), art. no. 611 .

13. Deng, Q., Penner, M.H., Zhao, Y. (2011). Chemical composition of dietary fiber and polyphenols of five different varieties of wine grape pomace skins. Food Research International, 44(9), 2712-2720.

14. Hong, N., Yaylayan, V.A., Vijaya Raghavan, G.S., Paré, J.R.J., Bélanger, J.M.R. (2001). Microwave-assisted extraction of phenolic compounds from grape seed. Natural Product Letters, 15(3), 197-204.

15. Kammerer, D., Claus, A., Carle, R., Schieber, A. (2004). Polyphenol screening of pomace from red and white grape varieties (Vitis vinifera L.) by HPLC-DAD-MS/MS. Journal of Agricultural and Food Chemistry, 52(14), 4360-4367.

16. Karvela, E., Makris, D.P., Kalogeropoulos, N., Karathanos, V.T., Kefalas, P. (2009). Factorial design optimisation of grape (Vitis vinifera) seed polyphenol extraction. European Food Research and Technology, 229(5), 731-742.

17. Krishnaswamy, K., Orsat, V., Gariépy, Y., Thangavel, K. (2013). Optimization of microwave-assisted extraction of phenolic antioxidants from grape seeds (Vitis vinifera). Food and Bioprocess Technology, 6(2), 441-455.

18. Ky, I., Lorrain, B., Kolbas, N., Crozier, A., Teissedre, P.-L. (2014). Wine by-products: Phenolic characterization and antioxidant activity evaluation of grapes and grape pomaces from six different French grape varieties. Molecules, 19(1), 482-506.

19. Ky, I., Teissedre, P.-L. (2015). Characterisation of Mediterranean grape pomace seed and skin extracts: Polyphenolic content and antioxidant activity. Molecules, 20(2), 2190-2207.

20. Laufenberg, G., Kunz, B., Nystroem, M. (2003). Transformation of vegetable waste into value added products: (A) the upgrading concept; (B) practical implementations. Bioresource Technology, 87(2), 167-198.

21. Li, Y., Skouroumounis, G.K., Elsey, G.M., Taylor, D.K. (2011). Microwave-assistance provides very rapid and efficient extraction of grape seed polyphenols. Food Chemistry, 129(2), 570-576.

22. Liazid, A., Guerrero, R.F., Cantos, E., Palma, M., Barroso, C.G. (2011). Microwave assisted extraction of anthocyanins from grape skins. Food Chemistry, 124(3), 1238-1243.

23. Lunze, J. (1998). Qualitative modelling of dynamical systems Motivation, methods, and prospective applications. Mathematics and Computers in Simulation, 46(5-6), 465-483.

24. Mané, C., Souquet, J.M., Ollé, D., Verriés, C., Véran, F., Mazerolles, G., Cheynier, V., Fulcrand, H. (2007). Optimization of simultaneous flavanol, phenolic acid, and anthocyanin extraction from grapes using an experimental design: Application to the characterization of Champagne grape varieties. Journal of Agricultural and Food Chemistry, 55(18), 7224-7233.

25. Mazor Jolić, S., Radojčic Redovnikovic, I., Marković, K., Ivanec Šipušić, D., Delonga, K. (2011). Changes of phenolic compounds and antioxidant capacity in cocoa beans processing. International Journal of Food Science and Technology, 46(9), 1793-1800.

26. Mazza, G., Fukumoto, L., Delaquis, P., Girard, B., Ewert, B. (1999). Anthocyanins, phenolics, and color of Cabernet Franc, Merlot, and Pinot Noir wines from British Columbia. Journal of Agricultural and Food Chemistry, 47(10), 4009-4017. 
27. Medouni-Adrar, S., Boulekbache-Makhlouf, L., Cadot, Y., Medouni-Haroune, L., Dahmoune, F., Makhoukhe, A., Madani, K. (2015). Optimization of the recovery of phenolic compounds from Algerian grape by-products. Industrial Crops and Products, 77, 123-132.

28. Ninfali, P., Mea, G., Giorgini, S., Rocchi, M., Bacchiocca, M. (2005). Antioxidant capacity of vegetables, spices and dressings relevant to nutrition. British Journal of Nutrition, 93(2), 257-266.

29. OIV - International Organisation of Vine and Wine. (2018, February 18). OIV 2018 report on the world vitivinicultural situation. Retrived from [http://www.oiv.int/public/medias/6371/oiv-statistical-report-on-world-vitiviniculture-2018.pdf].

30. Pedroza, M.A., Amendola, D., Maggi, L., Zalacain, A., De Faveri, D.M., Spigno, G. (2015). Microwave-assisted extraction of phenolic compounds from dried waste grape skins. International Journal of Food Engineering, 11(3), 359-370.

31. Peixoto, C.M., Dias, M.I., Alves, M.J., Calhelha, R.C., Barros, L., Pinho, S.P., Ferreira, I.C.F.R. (2018). Grape pomace as a source of phenolic compounds and diverse bioactive properties. Food Chemistry, 253, 132-138.

32. Pinelo, M., Rubilar, M., Jerez, M., Sineiro, J., Núñez, M.J. (2005). Effect of solvent, temperature, and solvent-to-solid ratio on the total phenolic content and antiradical activity of extracts from different components of grape pomace. Journal of Agricultural and Food Chemistry, 53(6), 2111-2117.

33. Ribéreau-Gayon, P., Stonestreet, E. (1966). Dosage des tanins $\mathrm{du}$ vin rouge et détermination de leur structure. Chimie Analytique, 48(4), 188-196 (in French).

34. Rodriguez-Rodriguez, R., Justo, M.L., Claro, C.M., Vila, E., Parrado, J., Herrera, M.D., Alvarez De Sotomayor, M. (2012). Endothelium-dependent vasodilator and antioxidant properties of a novel enzymatic extract of grape pomace from wine industrial waste. Food Chemistry, 135(3), 1044-1051.
35. Salarbashi, D., Khanzadeh, F., Hosseini, S.M., Mohamadi, M., Rajaei, A., Garmakhany, A.D. (2014). Prediction of the extraction yield using artificial neural network and response surface methodology: Ultrasound-assisted extraction from Achillea berbresteinii L. Quality Assurance and Safety of Crops and Foods, 6(4), 431-438.

36. Simić, V.M., Rajković, K.M., Stojičević, S.S., Veličković, D.T., Nikolić, N.Č., Lazić, M.L., Karabegović, I.T. (2016). Optimization of microwave-assisted extraction of total polyphenolic compounds from chokeberries by response surface methodology and artificial neural network. Separation and Purification Technology, 160, 89-97.

37. Singleton, V.L., Rossi, J.A. (1965). Colorimetry of total phenolics with phosphomolybdic-phosphotungstic acid reagents. American Journal of Enology and Viticulture, 16(3), 144-158.

38. Tournour, H.H., Segundo, M.A., Magalhães, L.M., Barreiros, L., Queiroz, J., Cunha, L.M. (2015). Valorization of grape pomace: Extraction of bioactive phenolics with antioxidant properties. Industrial Crops and Products, 74, 397-406.

39. Valls, J., Agnolet, S., Haas, F., Struffi, I., Ciesa, F., Robatscher, P., Oberhuber, M. (2017). Valorization of Lagrein grape pomace as a source of phenolic compounds: analysis of the contents of anthocyanins, flavanols and antioxidant activity. European Food Research and Technology, 243(12), 2211-2224.

40. Yilmaz, Y., Toledo, R.T. (2006). Oxygen radical absorbance capacities of grape/wine industry byproducts and effect of solvent type on extraction of grape seed polyphenols. Journal of Food Composition and Analysis, 19(1), 41-48.

Submitted: 7 March 2019. Revised: 23 April 2019. Accepted: 16 May 2019. Published on-line: 25 June 2019. 